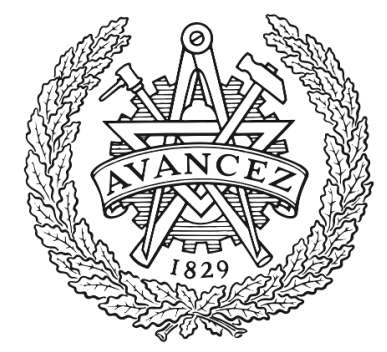

\title{
CHALMERS
}

UNIVERSITY OF TECHNOLOGY

\section{0-GHz Groove Gap Waveguide Based Wideband H-Plane Power Dividers and Transitions: For Use in High-Gain Slot Array Antenna}

Downloaded from: https://research.chalmers.se, 2023-04-26 13:34 UTC

Citation for the original published paper (version of record):

Farahbakhsh, A., Zarifi, D., Uz Zaman, A. (2017). 60-GHz Groove Gap Waveguide Based Wideband H-Plane Power Dividers and Transitions: For Use in

High-Gain Slot Array Antenna. IEEE Transactions on Microwave Theory and Techniques, 65(11):

4111-4121. http://dx.doi.org/10.1109/TMTT.2017.2699680

N.B. When citing this work, cite the original published paper.

(O2017 IEEE. Personal use of this material is permitted.

However, permission to reprint/republish this material for advertising or promotional purposes 


\title{
$60 \mathrm{GHz}$ Groove Gap Waveguide Based Wideband H-plane Power Dividers and Transitions: For Use in High Gain Slot Array Antenna
}

\author{
Ali Farahbakhsh, Davoud Zarifi, Ashraf Uz Zaman, Member, IEEE
}

\begin{abstract}
Wideband design of power dividers, T-junctions and transitions based on groove gap waveguide (GGW) technology is presented in this paper with the goal to use these components in high gain millimeter wave antenna array design at $60 \mathrm{GHz}$ frequency range. Since this groove gapwaveguide technology does not require electrical contact between the different metal layers of a complex 3-D waveguide structure, the fabrication cost and mechanical complexity are decreased. The designed $T$-junctions and different power dividers exhibit wide operational bandwidth and low output power and phase imbalance over the 60-GHz frequency band. Also, two transitions from GGW to a standard rectangular waveguide have been designed. To validate the performance of the designed components, a 64-way power divider in combination with 256 radiating slots is designed, prototyped and measured at $60-\mathrm{GHz}$ band. Measurement results agree well with the simulated performance of the complete array antenna and the antenna gain is more than $32.5 \mathrm{dBi}$. The total radiation efficiency is more than $80 \%$ over the operating frequency range from 57 to $67 \mathrm{GHz}$. Also, the measured sidelobe levels are found to be agreeing well with the simulated level.
\end{abstract}

Index Terms - Millimeter-wave techniques, gap waveguide technology, power divider, feeding network, slot antenna array.

\section{INTRODUCTION}

W ITH the emergence of various wireless applications in millimeter-wave frequency range, research on high frequency low loss passive components has gained lots of interest. Among various high frequency bands, the continuous and license free spectrum in $60 \mathrm{GHz}$ band is attracting researchers and scientists who are busy in developing future mm-wave communication systems [1]. Till now, the wireless networks operating in $60-\mathrm{GHz}$ band are limited to some special applications due to high path loss and attenuation of the radio wave in this band [2]. However, with the development of low loss waveguide components such as the

A. Farahbakhsh is with the School of Engineering, Graduate University of Advanced Technology, Kerman, Iran. D. Zarifi is with the School of Electrical Engineering, University of Kashan, Kashan, Iran. A. U. Zaman is with the Department of Signals and Systems, Chalmers University of Technology, SE41296 Göteborg, Sweden (e-mail: a_farahbakhsh@iust.ac.ir; zarifi@kashanu.ac.ir; zaman@chalmers.se)

The work has been supported by the European Research Council (ERC) via an advanced investigator grant ERC-2012- ADG 20120216, and by the VINNOVA smart electronics program with the project grant 2015-01387. band-pass filters and wideband antennas, the application areas for $60-\mathrm{GHz}$ wireless systems will be expanded in the future. Unfortunately due to small device dimensions, fabrication tolerances and good electrical joint requirements, it is challenging and expensive to fabricate low loss waveguide components by using conventional manufacturing techniques [3]-[5]. Also, a high-quality surface finish over the entire metal contact area is required for mechanical assembly. Protection against corrosion and oxidation must be applied to contacting surfaces over the product entire lifecycle [6]. Otherwise the losses in waveguides may increase dramatically due to field leakage via the gaps resulting from poor joints between the waveguide blocks. The imperfect metal contact among the metal walls and metal plates in regular waveguide causes field leakage and has been a problematic issue even at $\mathrm{Ku}$ band [7], let alone at millimeter wave frequencies. Expensive diffusion and metal welding is typically required to maintain good electric contact among waveguide blocks or joints [8], [9]. To overcome these issues, the gap waveguide technology was proposed in [10]-[12]. This proposed technology offers contactless waveguide structures in which good electrical joint or contact between the different metal layers is not required at all. Consequently, high-precision fabrication and mechanical assembly can be avoided and manufacturing cost of the waveguide filters or slot arrays can be minimized. Also, this gap waveguide technology suppresses unwanted parallel-plate modes in microstrip circuits.

In many microwave and millimeter-wave components and networks, the basic building blocks are power dividers. The power dividers have been widely used in couplers, diplexers and antenna feeding networks. As such a wideband power divider with high Q-factor and low loss is required in the feeding network of an array antenna, especially in the millimeter-wave frequency range. The traditional waveguide power dividers have the advantages of low insertion loss and capacity of high power handling, and therefore they can be used for array antenna feed networks, but high manufacturing tolerance is required to fabricate the components and overall cost limits their applications at mm-wave [13]-[17].

In this connection, the goal of this work is to deploy groove gap waveguide (GGW) technology to design different $\mathrm{T}$ junction and power dividers for slot array feed networks. In this technology, the propagation of the electromagnetic waves is controlled between two parallel plates without the requirement of electrical contact using the PEC/PMC cut-off 


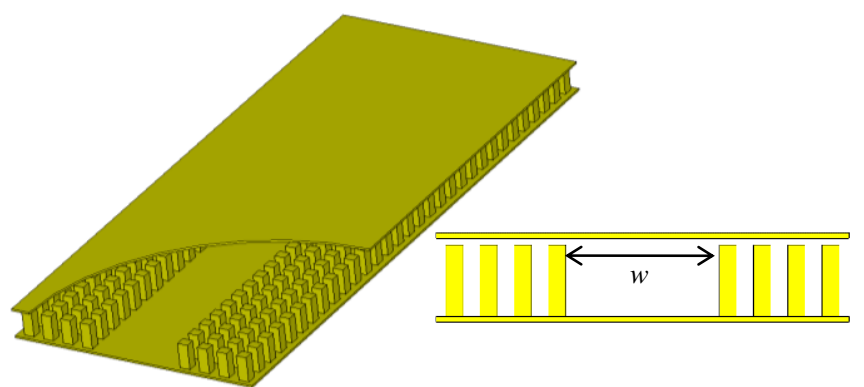

Perspective View

Front View

Fig. 1. The geometry of GGW structure.

conditions over the frequency band of interest [10]. This structure has a planar profile while being low loss and it is the main advantage compared to microstrip and SIW structures.

In addition, the advantage compared to conventional waveguide structure is that gap waveguide multilayer components can be made without any metal contacts between the different metal layers. The gap waveguide can be realized in different types such as groove, ridge and inverted microstrip. The ridges and grooves can be realized using a texture of metal pins without any dielectric. Since 2009 this technology has been introduced as a promising candidate to overcome the fabrication problems experienced with the traditional waveguide technologies at higher frequencies. Till now it has been proposed in several applications, such as antenna [18]-[23], microwave components [24]-[28] and RF packaging technology [29]-[31]. These structures can be mass produced by using regular molding or electric discharge machining where a complete metal layer will be produced in a single step and expensive CNC based metal milling can be avoided. All different metal layers can be assembled then easily with screws only.

In this paper, the design of a $\mathrm{T}$-junction power divider based on groove gap waveguide is presented which is the building block of bigger power dividers. The proposed $\mathrm{T}$-junction has equal output signals in amplitude and phase in a bandwidth more than $30 \%$. In order to excite GGW power dividers and to perform measurements, two types of transition from GGW to WR-15 are also proposed in this work. The results show about $30 \%$ of operating frequency impedance bandwidth $(|S 11|<$ $-20 \mathrm{~dB}$ ) from 52 to $70 \mathrm{GHz}$. Finally, a 64-way GGW power divider is deployed and used to feed a wideband, high gain and high efficiency slot array antenna.

The paper is organized as follows. Section II is devoted to the basic idea and details of GGW. Section III deals with the design procedure of $\mathrm{T}$-junction and power dividers based on GGW. Design of transition between GGW to rectangular waveguide is given in Section VI. In Section V, as an application, design of a complete feeding network based on GGW for a slot antenna array is discussed, and then details of fabrication and measurement are provided in Section VI. Finally, summary and conclusions are presented in Section VII.

\section{Groove GaP WAVEguide TeChNOLOGY}

Fig. 1 shows the groove gap waveguide geometry. As can be seen, a texture of metal pins is placed on a metal plate and a

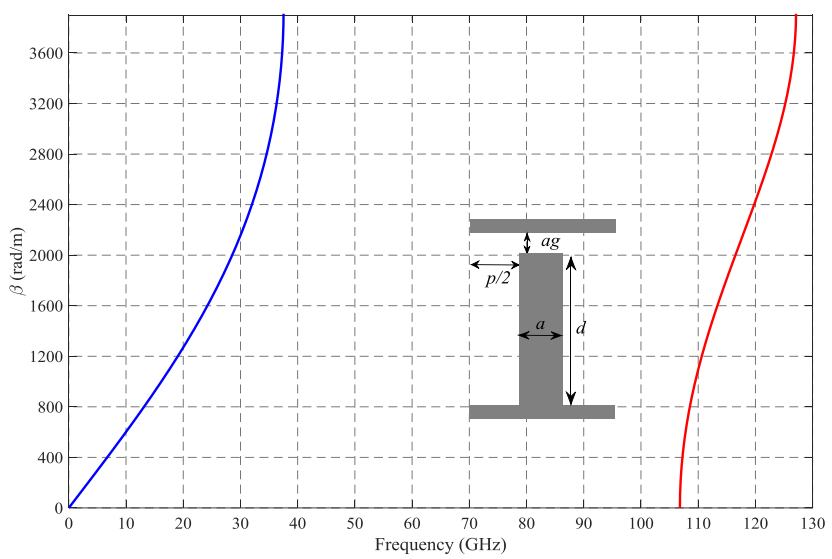

Fig. 2. Simulated dispersion diagram of an infinite periodic pin cell with dimensions of $a=0.4 \mathrm{~mm}, d=1.3 \mathrm{~mm}, p=0.4 \mathrm{~mm}$ and $a g=0.05 \mathrm{~mm}$.

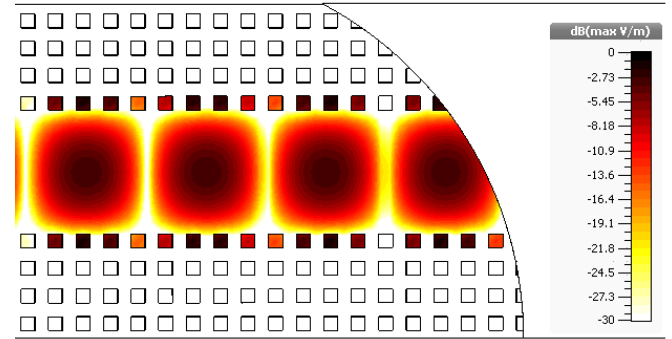

(a)

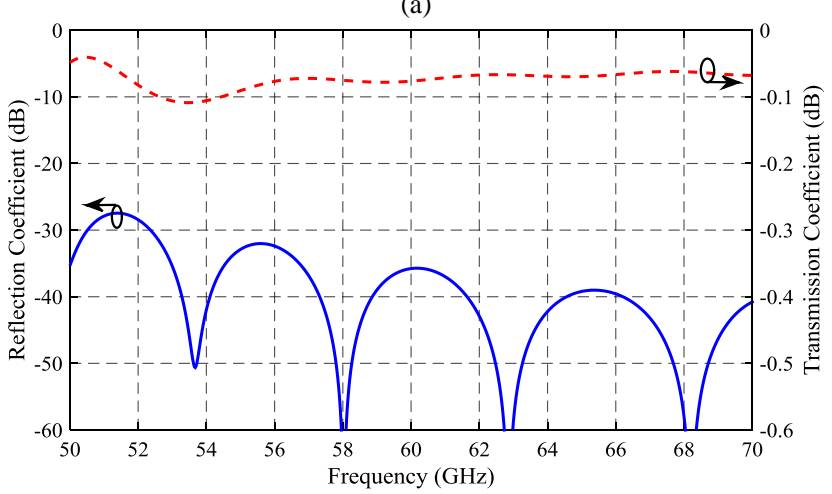

(b)

Fig. 3. (a) The simulated electric field distribution of the GGW at frequency $60 \mathrm{GHz}$. (b) The simulated reflection and transmission coefficients of the GGW structure.

grove is created in the middle. Unlike conventional metal waveguides, there is no need for electrical contact between the lower and upper metal plates. The pin surface plays the role of an artificial magnetic conductor and therefore, the propagation of waves in all lateral directions are stopped between the two plates within a frequency band known as stopband. The $\mathrm{TE}_{10}$ mode of the rectangular waveguides and the desired propagation mode of a groove gap waveguide are the same [10]-[12], [38].

Here, the dimensions of the pin's surface and the gap size are selected to achieve a stop-band covering $60-\mathrm{GHz}$ frequency band. The influence of varying pin dimensions in dispersion diagrams of the structure has been studied in detail in [11], [37]. According to these studies, the dimensions are chosen as the following: $d=1.3 \mathrm{~mm}, a=0.4 \mathrm{~mm}, a g=0.05$ $\mathrm{mm}, p=0.4 \mathrm{~mm}$. Fig. 2 shows the dispersion diagram of an infinite two-dimensional pin array. Then, a GGW is analyzed 


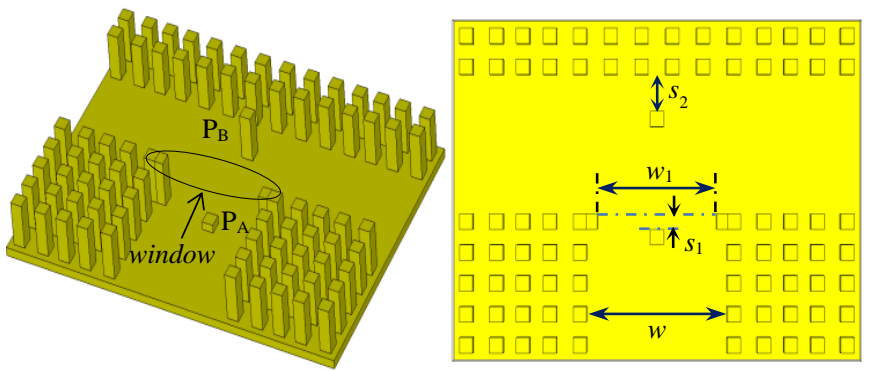

Fig. 4. The geometry of T-junction GGW power divider $\left(w=4.2, w_{1}=\right.$ $3.72, s_{1}=0.81, s_{2}=1.35$, unit: $\left.\mathrm{mm}\right)$. The heights of matching pins $\left(P_{A}\right.$ and $P_{B}$ ) are chosen as 0.32 and $1.3 \mathrm{~mm}$, respectively.

also in terms of dispersion diagram. The width of the groove $w$ is selected to be $0.5 \lambda$ at the lower cutoff of the pin surface $(50 \mathrm{GHz})$, i.e., $w=3 \mathrm{~mm}$. Within this stop-band, the allowed modes of the groove propagate and field leakage in the lateral direction can be controlled.

The electric field distribution of the structure at frequency $60 \mathrm{GHz}$ is shown in Fig. 3(a). This 2D plot shows that the field is quite confined on the groove. In fact, after the first row of pins the field decays really fast. This allows the design of arrays of waveguides with very low coupling between neighboring sections without requiring any metal contact between the two plates. Thereby, if some of these GGWs are manufactured sharing the same plates, they can be highly isolated requiring only one row of pins between them [22]. The reflection and transmission coefficients of a $20 \mathrm{~mm}$ long GGW structure are shown in Fig. 3(b).

\section{Design Of GGW T-Junction AND H-ShaPed Power DIVIDER}

\section{A. T-Junction GGW Power Divider}

The configuration of the T-junction based on GGW is illustrated in Fig. 4. The proposed topology provides in-phase power division with symmetrical amplitude distribution. As shown in the figure, this power divider is a GGW T-junction with opening window and pins to match the input port and split the incoming power from input port to the output ones. The height of the pin $P_{B}$ is kept the same as the height of all the other pins. But the height of $P_{A}$ is lowered and has been used as a tuning parameter. In order to satisfy the matching requirements over the desired frequency band, the position and height of matching pins and also the width of window are optimized. The final design parameters for the design are presented in Fig. 4.

To investigate the effect of the design parameters on the reflection coefficient of the structure, some parametric sweeps have been done for $S_{2}, P_{A}$ and $w_{1}$ parameters and the results are given in Fig. 5. According to the results one can find that the position of $P_{B}\left(S_{2}\right.$ parameter) has a large impact on the impedance matching, while the resonance frequency and bandwidth can be affected by $P_{A}$ and $w_{1}$, respectively.

Full-wave electromagnetic simulation of the design is performed with CST MWS and the simulation results are shown in Fig. 6. As can be seen, the input and outputs

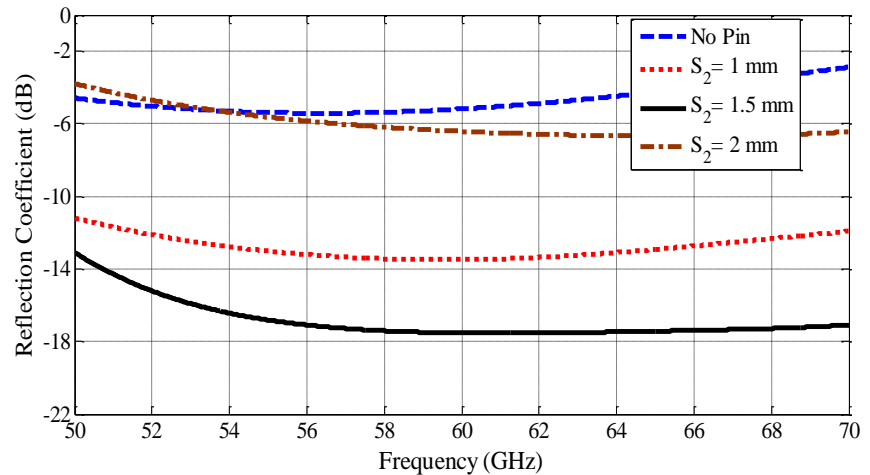

(a)

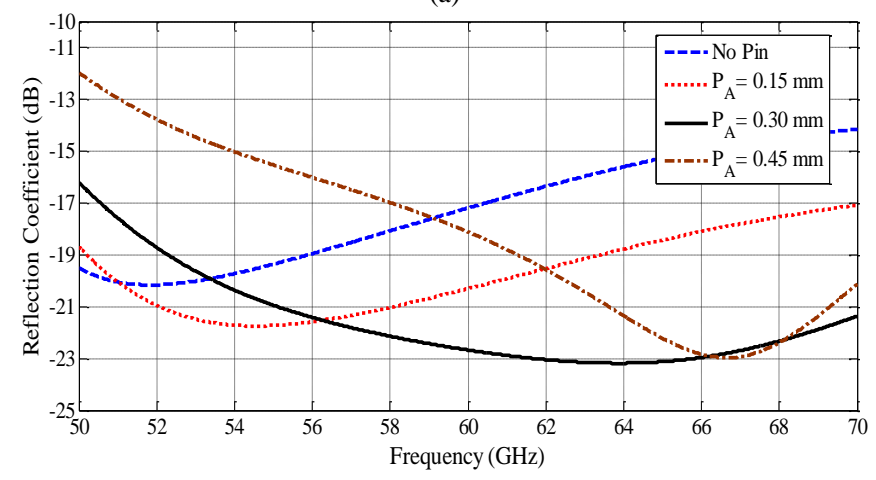

(b)

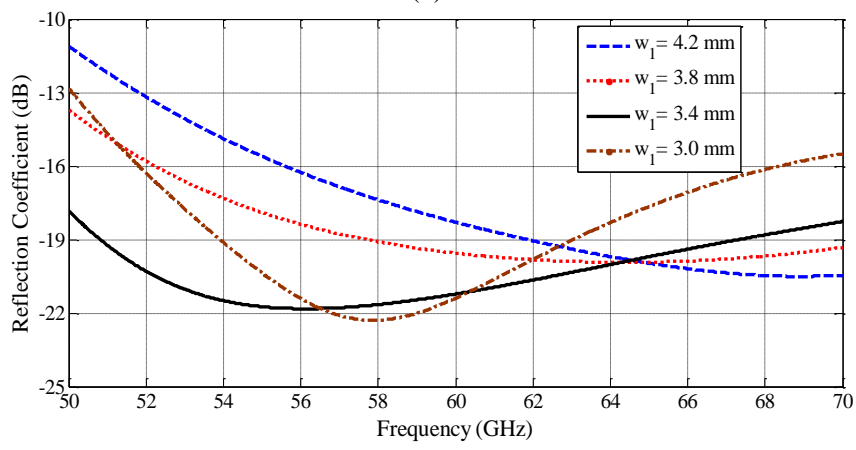

(c)

Fig. 5. Variation in parameter (a) $S_{2}$ (position of $P_{B}$ ) (b) $P_{A}$ (height of $P_{A}$ ) and (c) $w_{l}$ (width of the matching window)

matching for the T-junction power divider is better than $16 \mathrm{~dB}$ and the power is well equalized over the simulated bandwidth from 50-70 GHz. Observe that the amplitude and phase errors are nearly zero which is very important in antenna feeding networks. Also, the electric field distribution of the structure at frequency $60 \mathrm{GHz}$ is shown in Fig. 6(c).

The group delays for the GGW T-junction power divider and an ordinary rectangular waveguide power divider with the same dimensions are plotted in Fig. 6(d). As shown in the figure, the group delay of the GGW and ordinary power dividers are similar and the GGW power divider has an excellent small variation of $20 \mathrm{ps}$ across the entire bandwidth.

\section{B. Design of four-way Power Divider}

In this section, a physically symmetric $\mathrm{H}$-shaped four-way power divider with equal-phase and amplitude comprised of the pre-designed T-junction GGW power dividers is proposed. As shown in Fig. 7, the structure is symmetric with the center line of input GGW section. The required power-split ratio and 


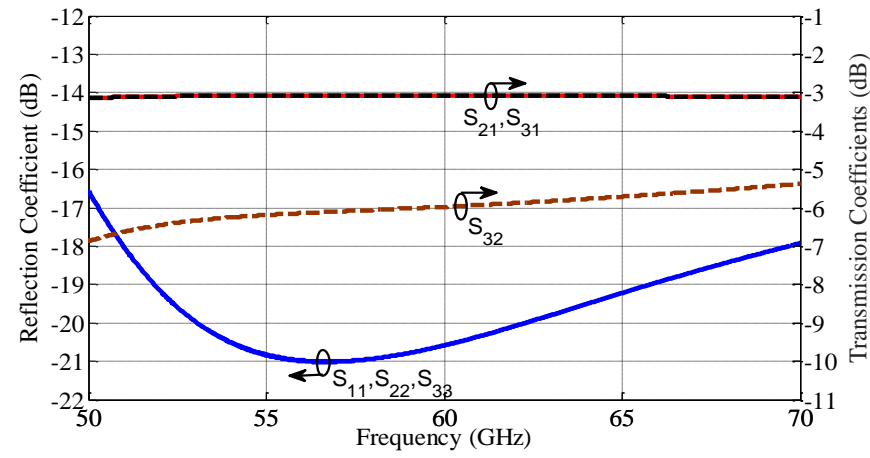

(a)

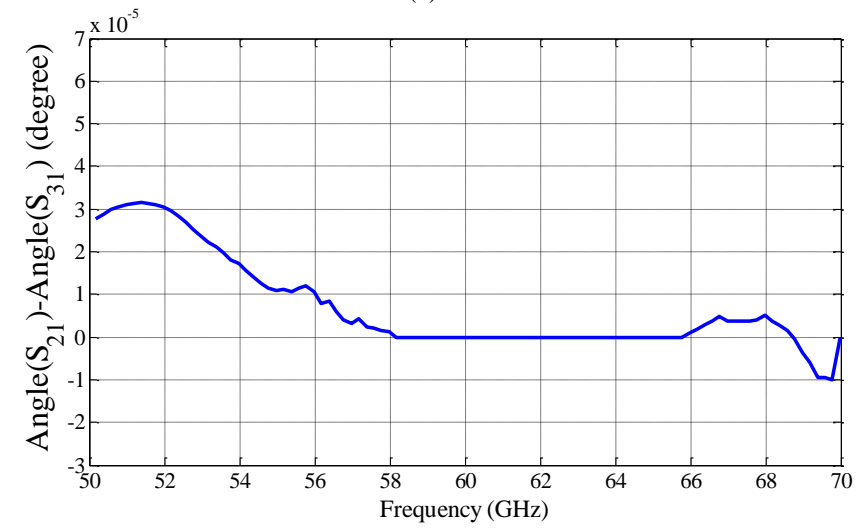

(b)

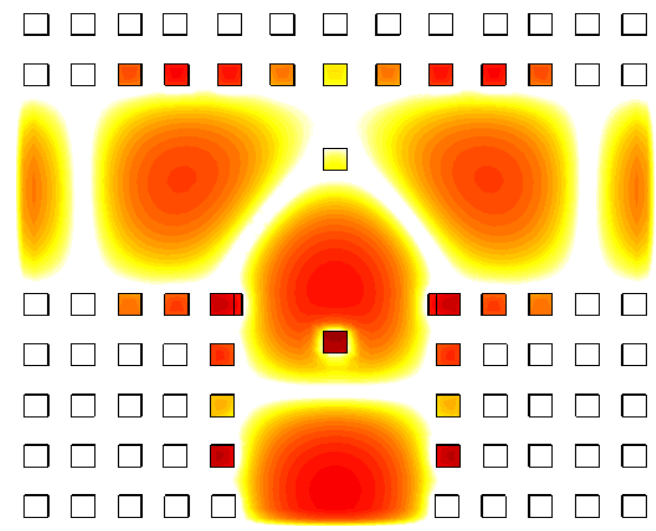

(c)

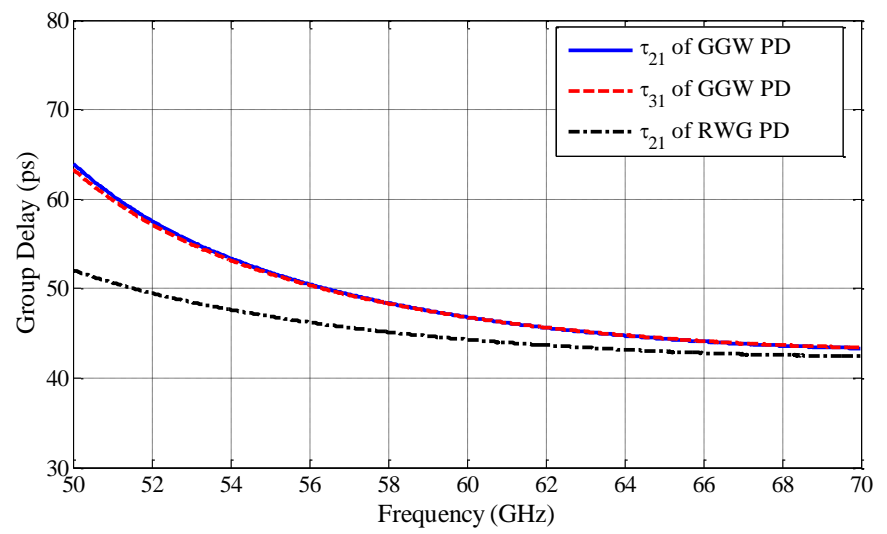

(d)

Fig. 6. (a) Simulation results for amplitudes of reflection and transmission coefficients. (b) Phase difference of outputs(c) electric field distribution at frequency $60 \mathrm{GHz}$ and (d) group delay variation for the T-junction GGW power divider in comparison with ordinary rectangular WG power divider.

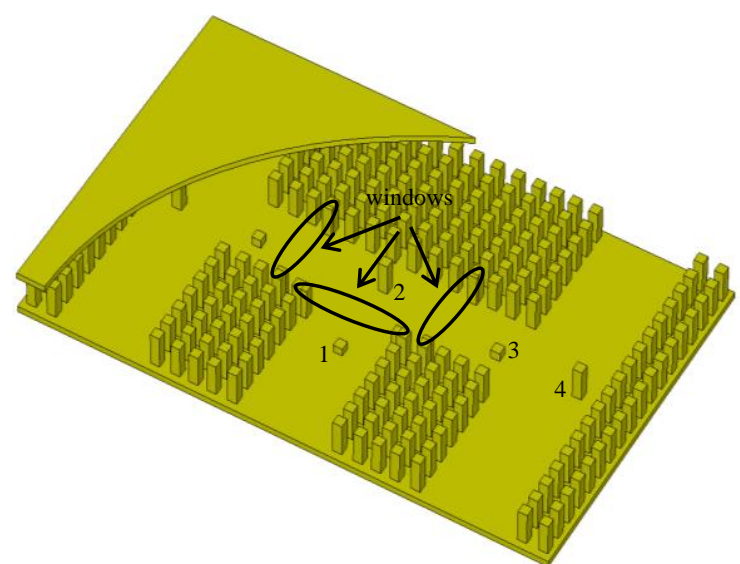

Fig. 7. Geometry of four-way H-shaped GGW power divider.

TABLE I. DESIGN PARAMETERS OF FOUR-WAY GGW POWER DIVIDER

\begin{tabular}{ccc}
\hline \hline Component & Parameter & Value (mm) \\
\hline \multirow{2}{*}{ Groove } & width & 4.2 \\
& height & 1.35 \\
Window 1 & width & 3.72 \\
& distance to junction & 0.0 \\
Windows 2 \& 3 & width & 3.28 \\
& distance to junction & 2.5 \\
Pin 1 & height & 0.32 \\
& distance to junction & 0.81 \\
Pin 2 & height & 1.3 \\
& distance to wall & 1.03 \\
Pin 3 & height & 0.36 \\
& distance to junction & 0.43 \\
Pin 4 & height & 1.3 \\
& distance to wall & 1.15 \\
\hline \hline
\end{tabular}

impedance matching are achieved by fine tuning the position and height of some matching pins and position and widths of windows. Observe that we use three windows and six matching pins for achieving good performance over the desired frequency band. The optimized values of the dimensions of the structure are given in Table I.

Numerical results shown in Fig. 8 reveal that near zero phase-balance can be maintained among the output ports. The power divider can also achieve stable power distribution in the bandwidth from $51 \mathrm{GHz}$ to $70 \mathrm{GHz}$ with a return loss better than $15 \mathrm{~dB}$.

The total variation of the group delay in the working bandwidth is about $23 \mathrm{ps}$, which is excellent for power divider applications, and is similar to the group delay of an ordinary rectangular waveguide power divider with the same dimensions.

Finally, a 16-way GGW power divider is realized by interconnecting pre-designed four-way power dividers, as shown in Fig. 9. The simulated input reflection of this 16-way GGW power divider is shown in Fig. 10. It can be seen that the overall performance of the 16-way power divider meets the specified bandwidth of the four-way divider very well. The 


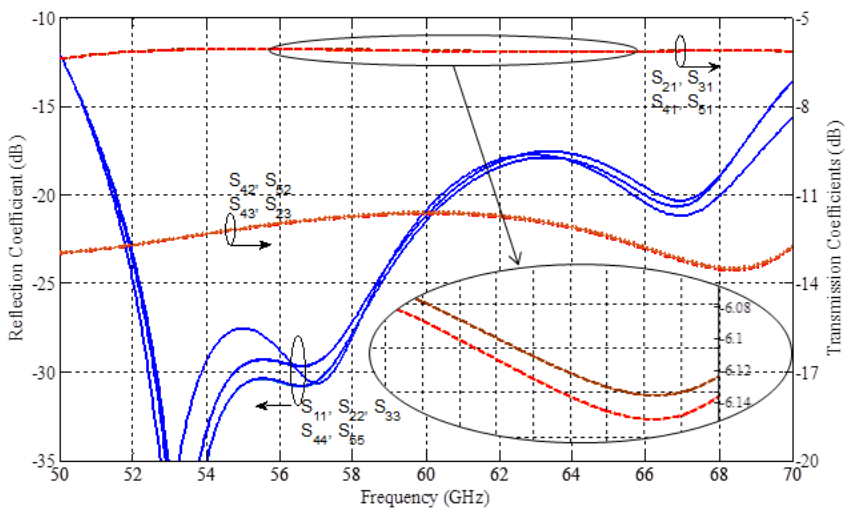

(a)

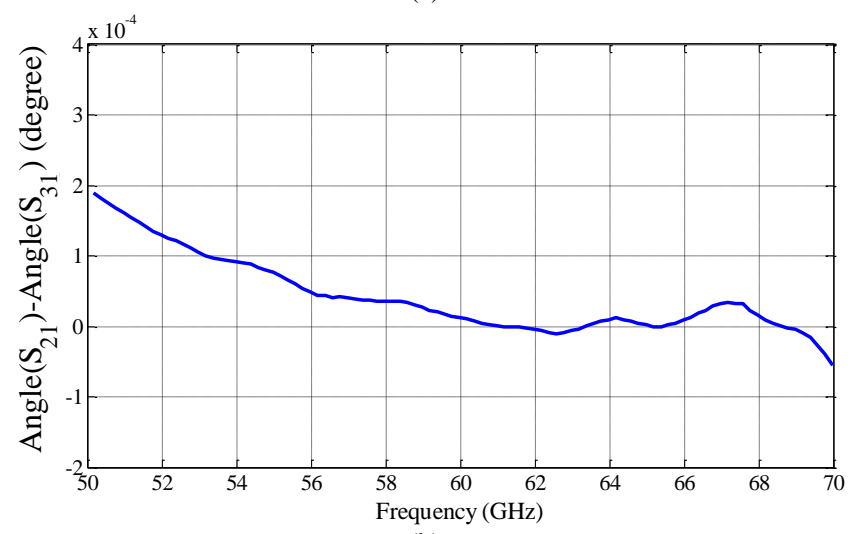

(b)

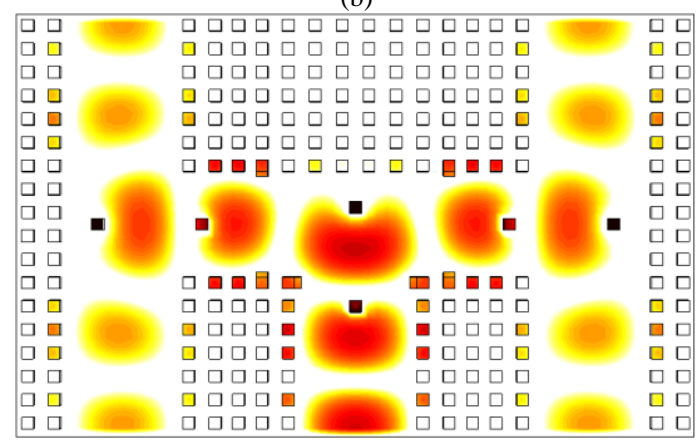

(c)

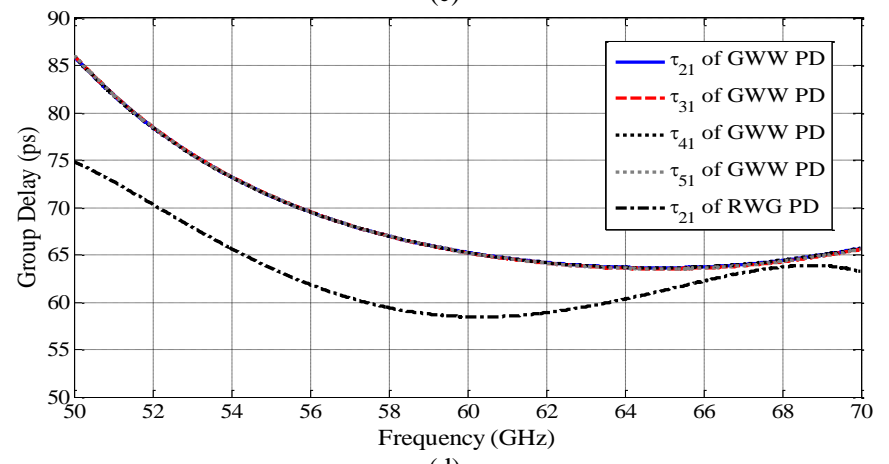

(d)

Fig. 8. (a) Simulation results for amplitudes of reflection and transmission coefficients, (b) phase difference of outputs (c) electric field distribution at frequency $60 \mathrm{GHz}$ and (d) group delay variation for the 4-way $\mathrm{H}$-shaped GGW power divider in comparison with ordinary rectangular WG power divider.

input reflection is better than $14 \mathrm{~dB}$ and the amplitude imbalance is better than $0.015 \mathrm{~dB}$ in the band of interest from 55-68 GHz.

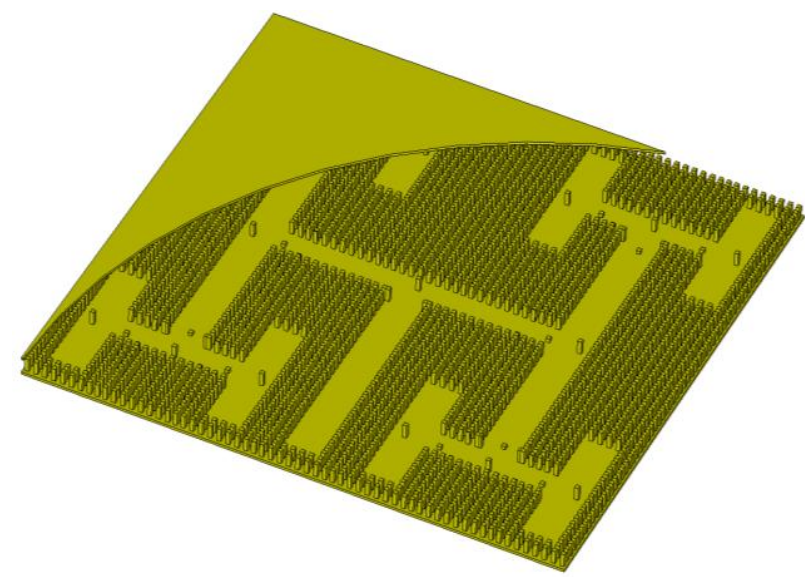

Fig. 9. Geometry of 16-way GGW power divider.

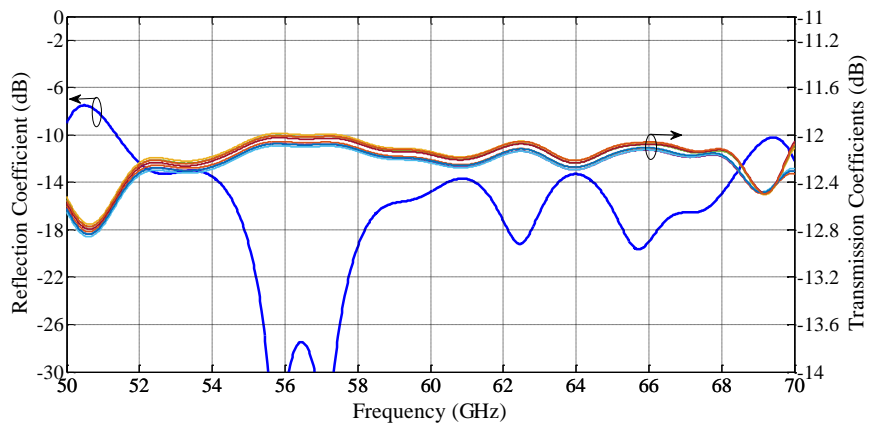

Fig. 10. Simulation results for amplitudes and phases of reflection and transmission coefficients of 16-way GGW power divider.

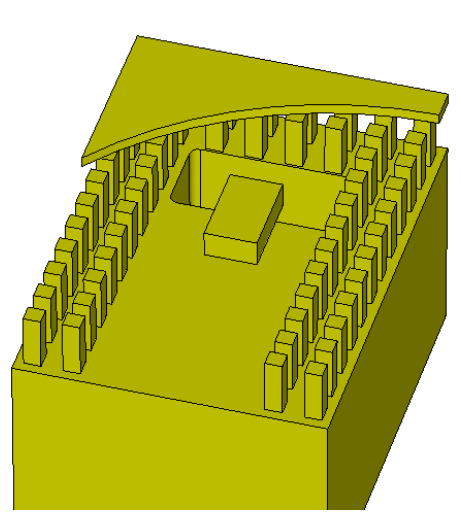

(a)

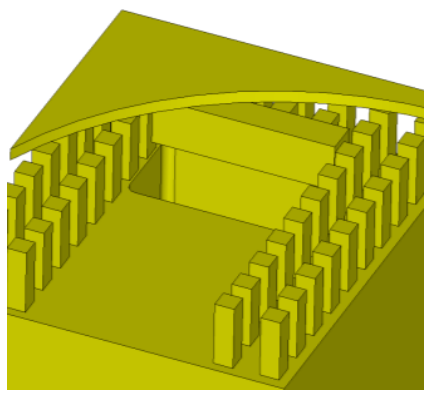

(c)

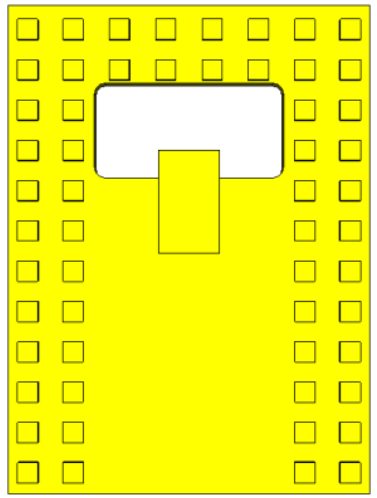

(b)

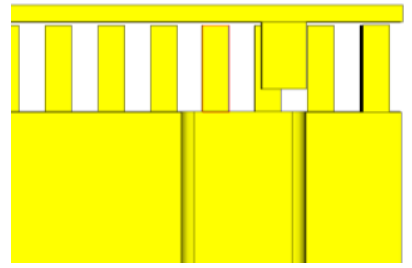

(d)
Fig. 11. GGW to WR-15 transitions. (a) type A perspective view, (b) type A top view, (c) type B perspective view and (d) type B side view. For type A : metal width $=1.45$, length $=2.05$ and height $=0.62$, unit:mm. For type B: metal width $=0.4$, length $=3.76$ and height $=1.22$, unit $: \mathrm{mm}$. 


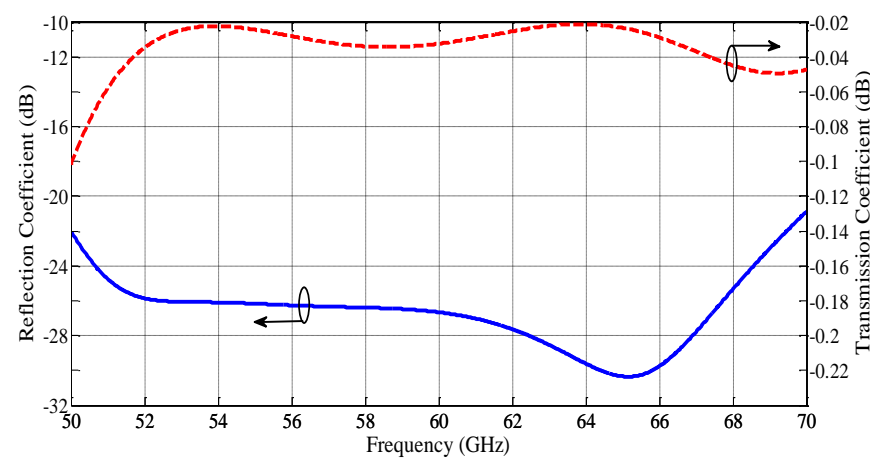

(a)

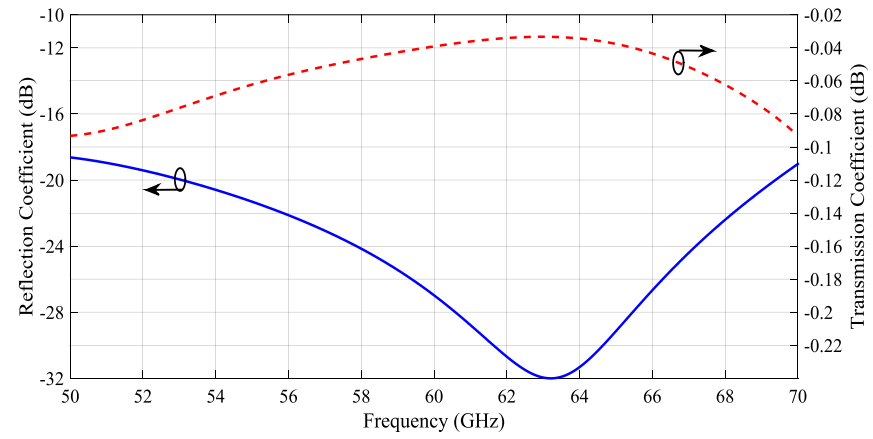

(b)

Fig. 12. Simulated reflection and transmission coefficients of two types of transitions from GGW to WR-15. (a) type A, (b) type B.

\section{Design of Transition From GGW to Rectangular WAVEGUIDE}

In practice, in order to excite GGW structures and to perform measurements, GGW structure should have a transition from GGW to a standard rectangular waveguide (e.g., WR-15). The transition transforms the electromagnetic fields from the rectangular waveguide mode to the GGW mode. The geometries of the proposed vertical transitions are shown in Fig. 11. The motivation for such a vertical transition is to use such transitions in the slot array antenna later on where it is convenient to excite the antenna from the back. Here, two types of GGW to WR-15 transitions are presented and named type A and type B. In the first one, only a metal brick section with an extension to the waveguide opening is necessary and this metal piece is placed on the bottom wall of the GGW as shown in Fig. 11(a)-(b). For achieving desired matching, parameters to be optimized in this transition are the length, width, height and position of the metal brick. The simulation results show a $24 \mathrm{~dB}$ return loss with an insertion loss better than $0.04 \mathrm{~dB}$ is achieved between $52-68 \mathrm{GHz}$.

In the second GGW to WR-15 transition, a metal brick is placed under the top wall of the GGW and above the waveguide opening as shown in Fig. 11(c)-(d). The simulations results of the transition type B are shown in Fig. 12(b). These transitions results are valuable for the design and evaluation of different GGW based microwave components at millimeter-wave frequencies. In this work, we use transition type A in the antenna array structure due to easier fabrication process.

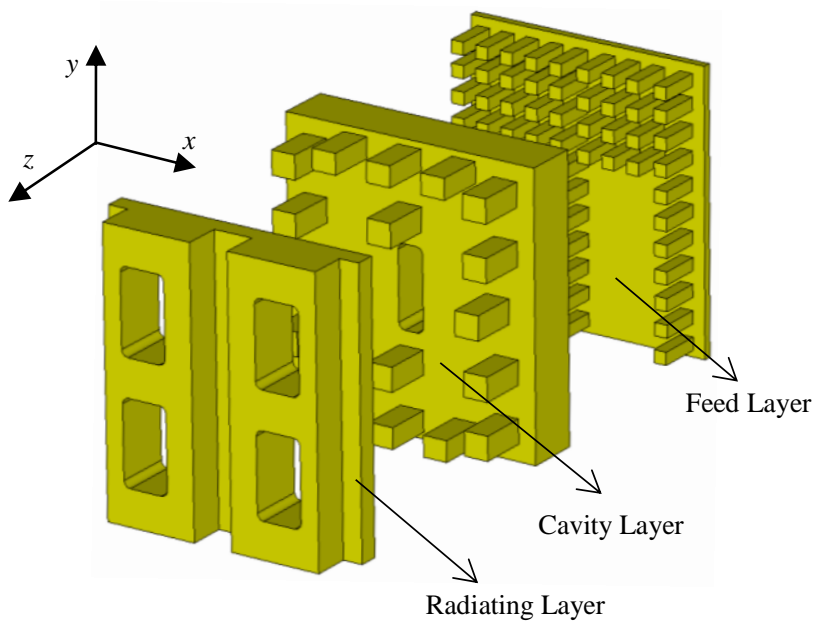

(a)

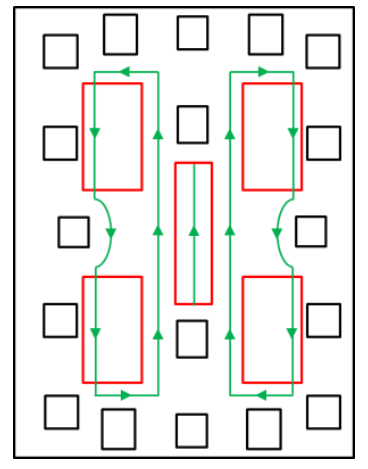

(b)

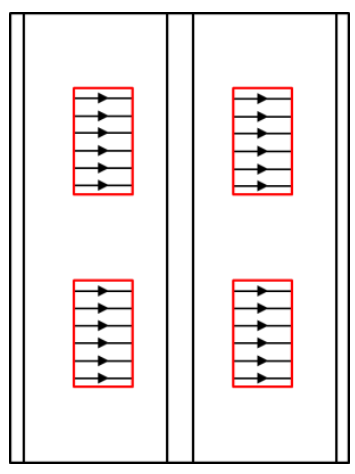

(c)
Fig. 13. (a) Exploded perspective view of basic $2 \times 2$-element sub-array. (b) magnetic field distribution in the cavity and (c) electric field distribution in radiating slots.

\section{APPlication of GGW POWER Divider As ANTENNA FEEDING NETWORK}

The antenna efficiency of a large planar antenna array is mainly determined by the losses of the feed network. In this section, in order to evaluate the performance of proposed GGW power dividers, we use a 64 -way GGW power divider as feed network of a $16 \times 16$-element slot antenna array.

\section{A. Basic $2 \times 2$-Element Sub-Array}

The overall geometry of $2 \times 2$-element sub-array is shown in Fig. 13. This structure includes the feeding network, the coupling slot and cavity, and the radiating slots. The feeding network is based on GGW and can be expanded to a bigger corporate feed network with many power dividers and Tjunctions. By proper design of cavity, four radiating slots are excited equally in amplitude and phase to give a broadside beam. Fig. 13(b) shows the magnetic field inside the cavity and, as can be seen, the magnetic field has the y component at the coupling slot. This creates similar magnetic field lines in two parts of the cavity as shown by the arrowed lines inside the cavity layer. These magnetic lines are cut by the radiating slots and as a result induce a perpendicular uniform electric field distribution in the $x$ direction in all the four radiating slots which is shown in Fig. 13(c). The pin dimensions of 


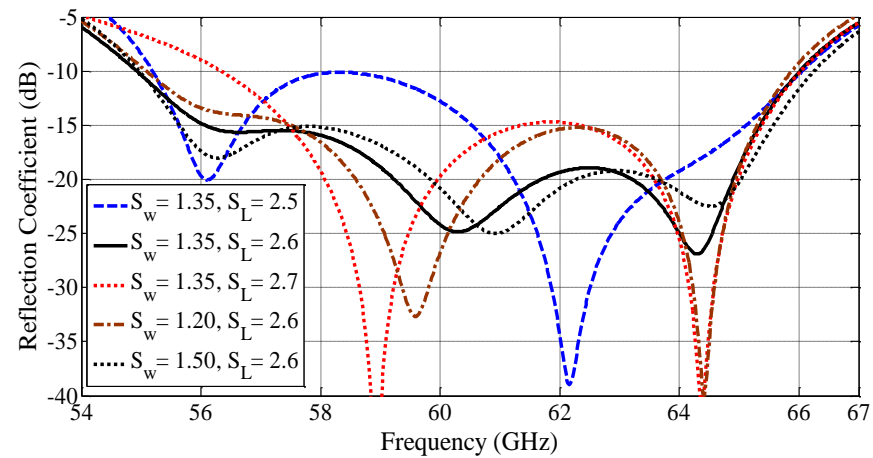

Fig. 14. Simulation results of variation in radiating slot width $\left(S_{w}\right)$ and length $\left(S_{L}\right)$; all dimensions are in $\mathrm{mm}$.

TABLE II. DetaILED Dimensions of ANTENNA Sub-ARRAY

\begin{tabular}{ccc}
\hline \hline \multirow{2}{*}{ Component } & Parameter & Value (mm) \\
\hline \multirow{3}{*}{ Radiating Slot } & length & 2.6 \\
& width & 1.35 \\
& spacing along $x$ & 3.7 \\
Corrugations & spacing along $y$ & 3.85 \\
& width & 1.2 \\
Coupling Slot & depth & 1.15 \\
& length & 2.57 \\
& width & 0.79 \\
Groove & offset from center of groove & 1.31 \\
& distance to back wall & 0.02 \\
& width & 3 \\
\hline \hline
\end{tabular}

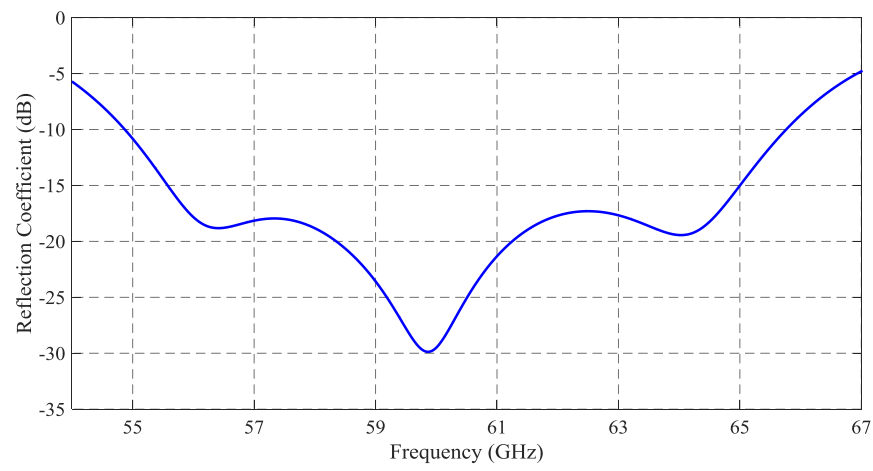

Fig. 15. Simulated $\left|S_{11}\right|$ of proposed sub-array.

cavity and feed layers are designed to obtain a stop-band covering from 40 to $80 \mathrm{GHz}$ [20]. Besides, it should be noticed that, for accurate assembly and also to decrease grating lobes, a thick metal plate with some corrugations is used in the radiating layer. The general properties of this type of slot array antennas have been discussed in [20]. In fact, the corrugations help in reducing the mutual coupling between the slot elements in E-plane and improve the radiation pattern and $S_{11}$ [20]. The corrugations depth and width are optimized to achieve satisfactory $S_{11}$ and radiation pattern of the antenna. To investigate the design parameter effects of the radiating slots, parametric sweeps have been done for several values of radiating slot widths and lengths, and the results are plotted in Fig. 14. As can be seen, the $S_{L}$ has a large impact on the

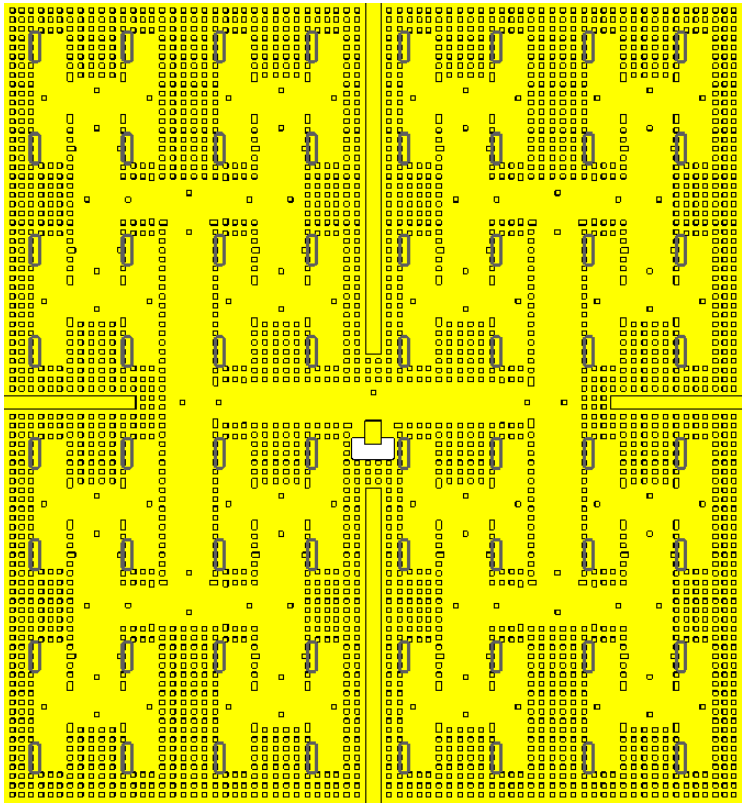

Fig. 16. Configuration of designed complete feed network of antenna.

resonance frequency and proper impedance matching can be obtained by tuning $S_{w}$.

Table II shows the final values of the structure dimensions. The antenna sub-array is designed at $60-\mathrm{GHz}$ band with the aid of a FEM based electromagnetic solver CST MWS. The simulated reflection coefficient of the sub-array with periodic boundary conditions in both $x$ - and $y$-directions is depicted in Fig. 15. The results demonstrate $18.2 \%$ of reflection coefficient bandwidth $\left(\left|\mathrm{S}_{11}\right|<-10 \mathrm{~dB}\right)$ covering $55-66 \mathrm{GHz}$ frequency range.

\section{B. Design of 64-way GGW Power Divider and 16×16- Elements Array Antenna}

A 64-way GGW power divider is utilized to feed the slot antenna array. This corporate feed network is depicted in Fig. 16. From the input port, the power is equally divided into 64 ports and then goes through the coupling slots to the cavity layer. After that, energy is radiated via the radiating slots in the radiating layer.

The minimum width of grooves and the minimum distance between adjacent grooves in the structure are 3 and $0.4 \mathrm{~mm}$, respectively. Also, notice that the adjacent grooves are isolated at least up to a $-20 \mathrm{~dB}$ level by putting only one row of pins between them [22].

\section{MEASUREMENT}

To verify the proposed design, a prototype of $16 \times 16$ element array antenna with full-corporate GGW feed network was fabricated in aluminum by metal milling technique, as shown in Fig. 17.

The reflection coefficient of the antenna array was measured by an Agilent PNA N5227A and V-band millimeter wave extender modules. The antenna was fed through a standard WR-15 waveguide. Fig. 18 shows the simulated and measured reflection coefficients for the antenna. As can be seen, the 

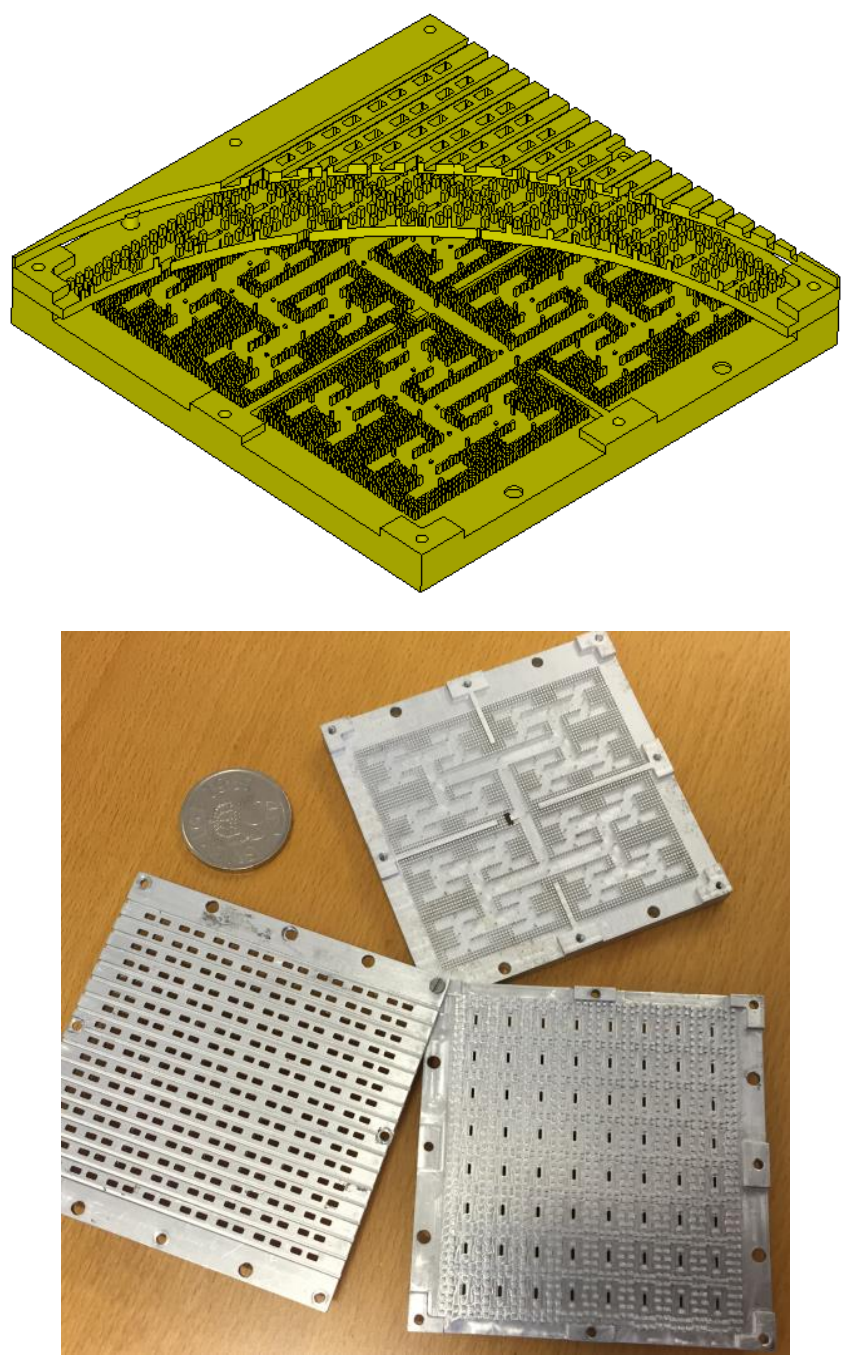

Fig. 17. Final structure of antenna array with $16 \times 16$-slots and fabricated antenna photo. The dimensions of the structure are of $80 \times 80 \times 12.2 \mathrm{~mm}^{3}$.

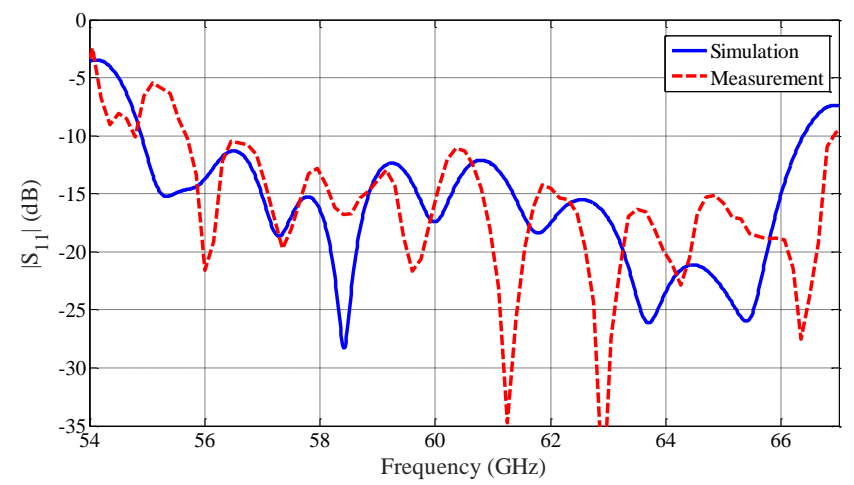

Fig. 18. Measured and simulated reflection coefficients of the whole structure.

fabricated antenna has an impedance bandwidth $(\mathrm{SWR} \leq 2)$ of $18.8 \%$ covering 55.5 to $67 \mathrm{GHz}$. Generally, the measured results are in quite good agreement with the simulated ones. However there are some differences between them due to manufacturing and assembling tolerances.

The measured and simulated gains of the array antenna versus frequency are plotted in Fig. 19. The maximum available directivity of a radiating aperture having dimensions

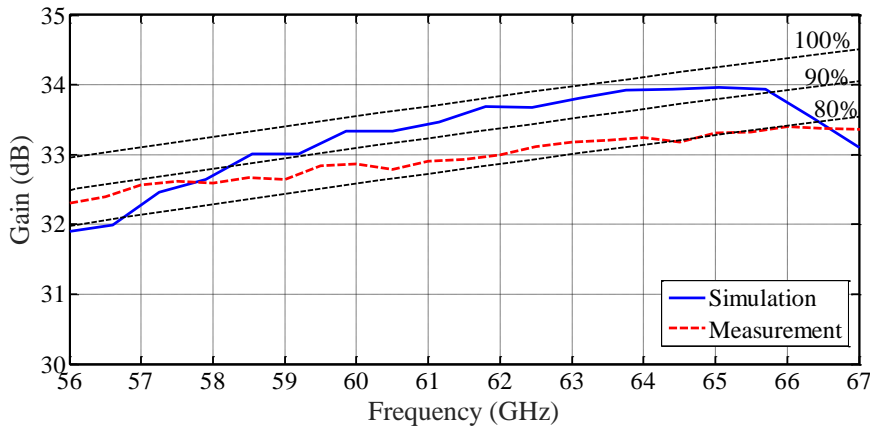

Fig. 19. Measured and simulated gain of whole structure and $100 \%, 90 \%$ and $80 \%$ efficiency lines.

TABle III. COMPARISON OF DifFERENT 60 GHz Planar Slot Antenna ARRAYS

\begin{tabular}{|c|c|c|c|c|c|}
\hline & Our work & Ref. [20] & Ref. [32] & Ref. [35] & Ref. [36] \\
\hline Size (cm) & $70 \times 64$ & $70 \times 64$ & $67 \times 67$ & $52 \times 52$ & $34 \times 35$ \\
\hline $\begin{array}{c}\text { Number of } \\
\text { Elements }\end{array}$ & 256 & 256 & 256 & 256 & 64 \\
\hline $\begin{array}{c}\text { Frequency } \\
\text { Band } \\
\text { (GHz) }\end{array}$ & $55.5-67$ & $56-65.7$ & $59-64$ & $57-66$ & $56.3-65.7$ \\
\hline $\begin{array}{c}\text { Bandwidth } \\
\text { (G.8\% }\end{array}$ & $18 \%$ & $8 \%$ & $14.6 \%$ & $15.7 \%$ \\
\hline Gain (dBi) & $>32.5$ & $>32.5$ & $>32$ & $>28$ & $>22$ \\
\hline Efficiency & $>80 \%$ & $>70 \%$ & $>70 \%$ & $<50 \%$ & $<42 \%$ \\
\hline Technology & $\begin{array}{l}\text { Groove Gap } \\
\text { Waveguide }\end{array}$ & $\begin{array}{c}\text { Ridge Gap } \\
\text { Waveguide }\end{array}$ & $\begin{array}{c}\text { Plaminated } \\
\text { laminat }\end{array}$ & SIW & LTCC \\
\hline
\end{tabular}

of $70.4 \times 64 \mathrm{~mm}^{2}$ and when aperture efficiency is $80 \%, 90 \%$ and $100 \%$, are shown by dotted lines. The realized gain at the design frequency band is more than $32.5 \mathrm{~dB}$ and the corresponding efficiency is more than $80 \%$. The realized gain actually takes into account all the losses in the antenna, including the losses in the feed network and losses in the transition. The difference between the simulated losses and measured losses differ by about $0.5 \mathrm{~dB}$ in this case. This extra loss in measurement is attributed to the ohmic losses due to lower conductivity of the material in presence of surface roughness which is not considered in simulation.

The simulated and measured antenna radiation patterns at some frequencies in the E-, $\mathrm{H}$ - and $45^{\circ}$-planes are depicted in Figs. 20 and 21, respectively. Observe that the first sidelobe levels of the simulated and measured radiation patterns are very close to the theoretical value of a uniform aperture which is around $-13 \mathrm{~dB}$. This sidelobe level and also the symmetric radiation patterns in all planes show the excellent performance of power divider and feeding network of the antenna array.

Compared with similar $60-\mathrm{GHz}$ antenna arrays discussed in the literature, the proposed structure is wideband and has high efficiency and radiation gain. The performances of different planar slot antenna arrays are compared in Table III. 


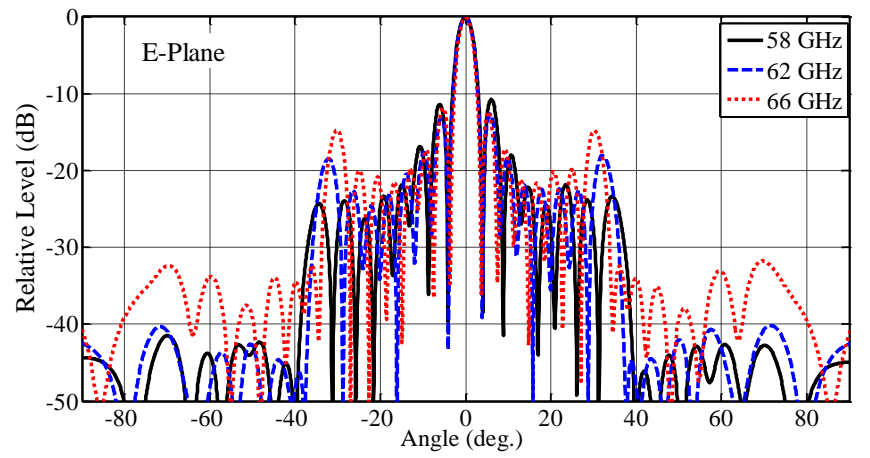

(a)

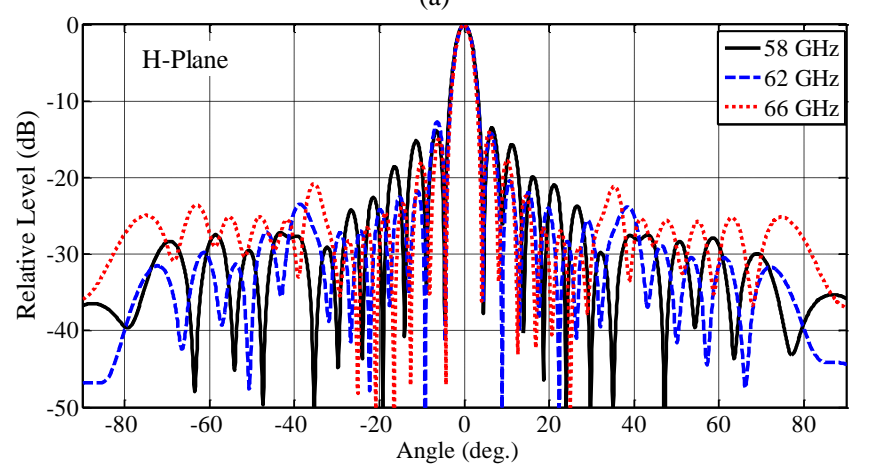

(b)

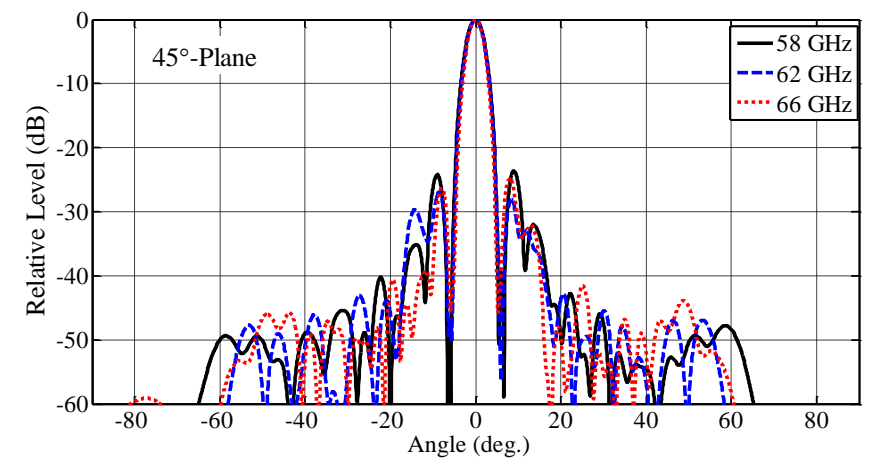

(c)

Fig. 20. Simulated radiation patterns of antenna array at E-, H- and $45^{\circ}$-planes at frequencies 58, 62 and $66 \mathrm{GHz}$.

The losses and total efficiencies in SIW based antenna are an important problem, especially for high-gain antennas when the dimension of the SIW array becomes larger; however, the losses are lower than in microstrip structures [33]-[36]. In these antennas the total efficiency of antenna is less than $50 \%$ typically. Also, the total efficiency of our GGW based antenna is higher than that of similar ridge gap waveguide based antenna presented in [20]. This can be attributed to lower loss of groove structures rather than ridge structures discussed in [25], [37].

\section{CONCLUSION}

This paper focuses on the design of wideband power divider for millimeter-wave applications based on GGW technology. In case of critical multi-layer microwave structure, the need of electrical contact between the different layers can be eliminated by using GGW technology. We have demonstrated the design of $\mathrm{H}$-plane $3-\mathrm{dB}$ power dividers in GGW technology and also designed important transition from
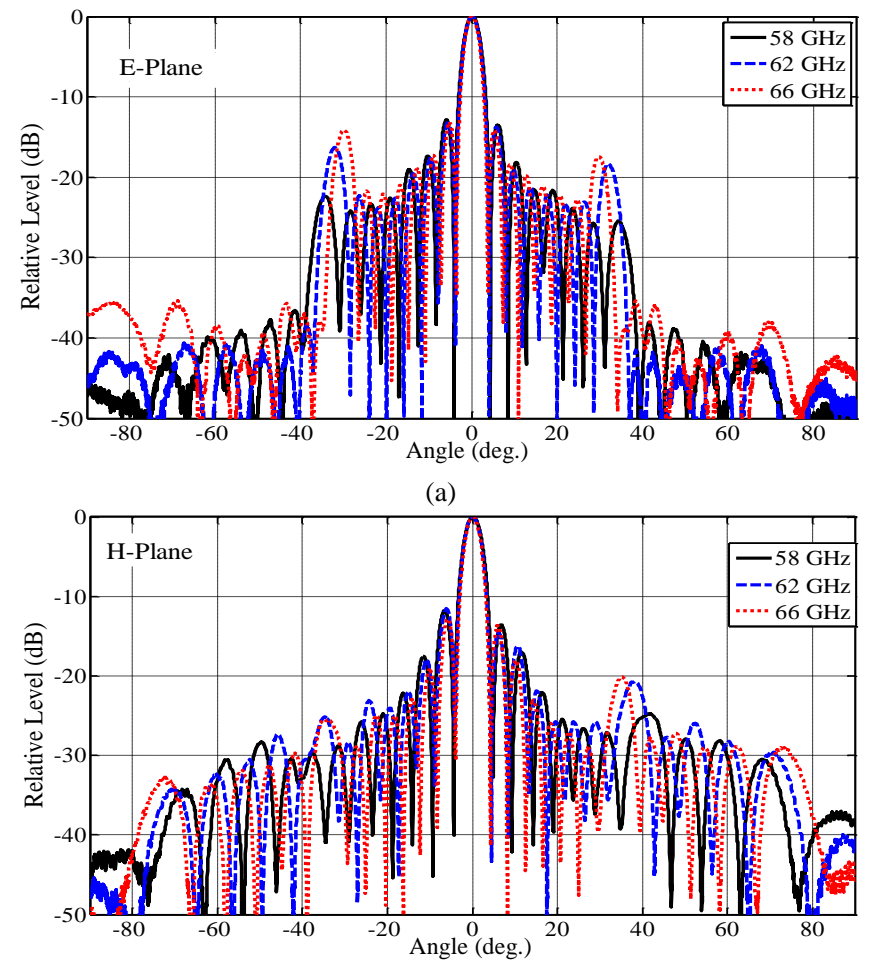

(b)

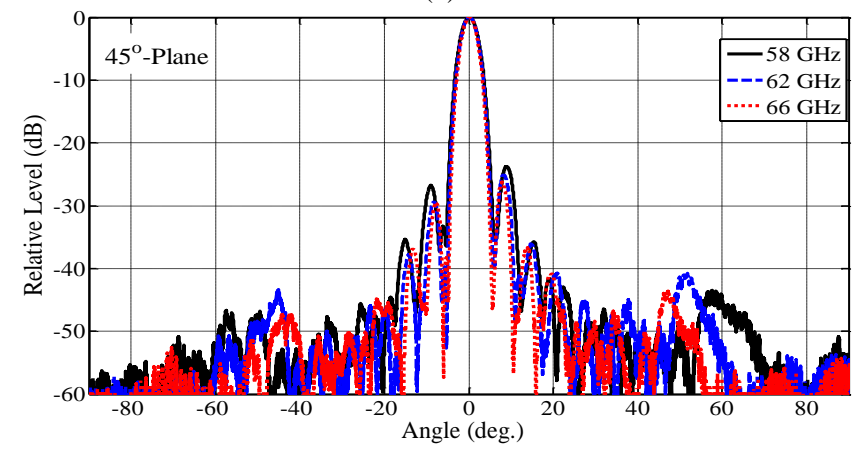

(c)

Fig. 21. Measured radiation patterns of antenna array at E-, $\mathrm{H}$ - and $45^{\circ}$-planes at frequencies 58, 62 and $66 \mathrm{GHz}$.

GGWG to RWG. The GGW power dividers benefit from low insertion losses, capacity of high power handling, low cost fabrication and ease of application in millimeter-wave components. Finally, a 64-way GGW power divider has been designed and used to feed a slot antenna array. A measured gain higher than $33 \mathrm{dBi}$ with total radiation efficiency of higher than $80 \%$ over the entire operation bandwidth from 57 to $66 \mathrm{GHz}$ is achieved. Measured radiation patterns over the band of interest have confirmed the performance of GGW power divider and the designed transitions. It can be concluded that the GGW feed networks are attractive candidates for practical millimeter-wave applications considering the tradeoff between performance and fabrication costs.

\section{ACKNOWLEDGMENT}

The authors would like to gratefully acknowledge late Prof. Per-Simon Kildal from Chalmers University, Sweden for his sincere support during this work. He passed away 
unexpectedly before this paper could be submitted for review. Many of the ideas and concepts presented in this paper have been stimulated after several meetings and discussion with him.

\section{REFERENCES}

[1] M. R. Yuce, Ultra-Wideband and $60 \mathrm{GHz}$ Communications for Biomedical Applications, Springer, New York, 2014.

[2] Y. P. Zhang and D. X. Liu, "Antenna-on-chip and antenna-in-package solutions to highly integrated millimeter-wave devices for wireless communications," IEEE Trans. Antennas Propag., vol. 57, no. 10, pp. 2830-2841, Oct. 2009.

[3] H. Uchimura, T. Takenoshita, and M. Fujii, "Development of a laminated waveguide," IEEE Trans. Microw. Theory Techn., pp. 24382443 , vol. 46 , no. $12,1998$.

[4] D. Deslandes and K.Wu, "Integrated microstrip and rectangular waveguide in planar form," IEEE Microw. Wireless Compon. Let., vol. 11, no. 2, pp. 68-70, Feb. 2001.

[5] F. Xu, K.Wu, "Guided-wave and leakage characteristics of substrate integrated waveguide," IEEE Trans. Microw. Theory Techn., vol. 53, no. 1, pp. 66-73, 2005.

[6] D. Liu, B. Gaucher, U. Pfeiffer, and J.Grzyb, "Advanced MillimeterWave Technologies: Antennas, Packaging and Circuits," John Wiley \& Sons, 2009.

[7] S. G. Zhou, G. L. Huang, T. H. Chio, J. J. Yang, and G. Wei, "Design of a Wideband Dual-Polarization Full-Corporate Waveguide Feed Antenna Array," IEEE Transactions on Antennas and Propagation, vol. 63, no. 11, pp. 4775-4782, Nov. 2015.

[8] J. Hirokawa, Z. Miao, and M. Ando, "Millimeter waveguide fabrication to reduce transmission loss by diffusion bonding, light-curing resin or dielectric partially-filling," in Asia Pacific Microwave Conference (APMC), pp. 1-4, 2008.

[9] K. Sakakibara, Y. Kimura, A. Akiyama, J. Hirokawa, M. Ando, and N. Goto, "Alternating phase-fed waveguide slot arrays with a single-layer multiple-way power divider," in IEE Proceedings - Microwaves, Antennas and Propagation, vol. 144, no. 6, pp. 425-430, Dec 1997.

[10] P.-S. Kildal, E. Alfonso, A. Valero-Nogueira, and E. Rajo-Iglesias, "Local metamaterial-based waveguides in gaps between parallel metal plates," IEEE Antennas Wireless Propag. Lett., vol. 8, no. , pp. 84-87, 2009.

[11] E. Rajo-Iglesias and P.-S. Kildal, "Numerical studies of bandwidth of parallel plate cut-off realized by bed of nails, corrugations and mushroom-type EBG for use in gap waveguides," IET Microw., Antennas Propag., vol. 5, no. 3, pp. 282-289, Mar. 2011.

[12] P.-S. Kildal, A. U. Zaman, E. Rajo-Iglesias, E. Alfonso, and A. ValeroNogueira, "Design and experimental verification of ridge gap waveguides in bed of nails for parallel plate mode suppression," IET Microw., Antennas Propag., vol. 5, no. 3, pp. 262-270, Mar. 2011.

[13] T. Djerafi, A. Patrovsky, K. Wu, S. O. Tatu, "Recombinant Waveguide Power Divider," IEEE Transactions on Microwave Theory and Techniques, vol. 61, no. 11, pp. 3884-3891, November 2013.

[14] S. Park, Y. Tsunemitsu, J. Hirokawa, and M. Ando, "Center feed single layer slotted waveguide array," IEEE Trans. Antennas Propag., vol. 54, no. 5, pp. 1474-1480, May 2006.

[15] K. Song, Y. Fan, and Z. He, "Broadband radial waveguide spatial combiner," IEEE Microw. Wireless. Compon. Lett., vol. 18, no. 2, pp. $73-75,2008$

[16] Soroka, A. S., A. O. Silin, V. I. Tkachenko, and I. S. Tsakanyan, "Simulation of multichannel waveguide power dividers," Physics and Engineering of Millimeter and Submillimeter Waves Symposium, Kharkov, Ukraine, pp. 634-635, Sep.1998.

[17] D. Deslandes, F. Boone, and K. Wu, "Universal single layer waveguide power divider for slot array antenna applications", IEEE MTT-S Int. Microw. Symp. Dig., pp. 431-434, 2007.

[18] E. Pucci, E. Rajo-Iglesias, J. L. Vazquez-Roy, and P. S. Kildal, "Planar Dual-Mode Horn Array With Corporate-Feed Network in Inverted Microstrip Gap Waveguide," IEEE Trans. Antennas Propag. , vol. 62, no. 6, pp. 3534-3542, 2014.

[19] A. Razavi, P.-S. Kildal, X. Liangliang, E. Alfonso, and H. Chen, "2x2slot Element for $60 \mathrm{GHz}$ Planar Array Antenna Realized on Two Doubled-sided PCBs Using SIW Cavity and EBG-type Soft Surface fed by Microstrip-Ridge Gap Waveguide," IEEE Trans. Antennas Propag. , vol. 62, no. 9, pp. 4564-4573, Sep. 2014.
[20] D. Zarifi, A. Farahbakhsh, A. U. Zaman, and P. S. Kildal, "Design and Fabrication of a High-Gain $60-\mathrm{GHz}$ Corrugated Slot Antenna Array With Ridge Gap Waveguide Distribution Layer," IEEE Trans. Antennas Propag., vol. 64, no. 7, pp. 2905-2913, July 2016.

[21] A. Vosoogh and P. S. Kildal, "Corporate-Fed Planar 60 GHz Slot Array Made of Three Unconnected Metal Layers Using AMC pin surface for the Gap Waveguide," IEEE Antenna Wireless Propagation Letter., vol. 15, no. , pp. 1935-1938, Dec. 2015.

[22] A. U. Zaman and P. S. Kildal, "Wide-Band Slot Antenna Arrays With Single-Layer Corporate-Feed Network in Ridge Gap Waveguide Technology," IEEE Trans. Antennas Propag., vol. 62, no. 6, pp. 29923001, June 2014.

[23] B. Cao, H. Wang, and Y. Huang, "W-Band High-Gain TE -Mode Slot Antenna Array With Gap Waveguide Feeding Network," IEEE Antenna Wireless Propagation Letters, vol. 15, no. , pp. 998-991, 2016.

[24] A. U. Zaman, P. S. Kildal, and A. Kishk, "Narrow-Band Microwave Filter Using High-Q Groove Gap Waveguide Resonators With Manufacturing Flexibility and No Sidewalls," IEEE Trans. Comp. Pack. Manufact. Technol., vol. 2, no. 11, pp. 1882-1889, November 2012.

[25] E. Pucci, A. U. Zaman, E. Rajo-Iglesias, P.-S. Kildal, and A. Kishk, "Study of Q factors of ridge and groove gap waveguide resonator," IEEE Trans. Compon., Packag. Manuf. Technol., vol. 7, no. 11, pp. 900-908, November 2013.

[26] A. U. Zaman, V. Vassilev, P.-S Kildal, and H. Zirath, "Millimeter Wave E-Plane Transition From Waveguide to Microstrip Line With Large Substrate Size Related to MMIC Integration," IEEE Microwave and Wireless Components Letters, vol. 26, no. 7, pp. 481-483, July 2016.

[27] A. Alfonso, A. U. Zaman, and P.-S. Kildal, "Ka-Band Gap Waveguide Coupled-Resonator Filter for Radio Link Diplexer Application," IEEE Trans. Comp. Pack. Manufact. Technol., vol. 3, no. 5, pp. 870-879, 2013.

[28] A. Berenguer, D. Sánchez-Escuderos, B. Bernardo-Clemente, M. Baquero-Escudero, and V.E. Boria, "Groove gap waveguide as an alternative to rectangular waveguide for H-plane components," Electronic Letters, vol. 52, no. 11, pp. 939-941, May 2016.

[29] E. Alfonso, A. U. Zaman, E. Pucci, and P. S. Kildal, "Gap waveguide components for millimeter-wave system: coiplers, filters, antenna, MMIC and packaging," International Symposium on Antennas and Propagation (ISAP) 2012, Japan, pp. 243-246, 2012.

[30] A. U. Zaman, M. Alexanderson, T. Vukusic, and P.-S. Kildal, "Gap waveguide PMC packaging for improved isolation of circuit components in high-frequency microwave modules," IEEE Trans. Comp. Pack. Manufact. Technol., vol. 4, no. 1, pp. 16-25, 2014.

[31] J. Zhang, X. Zhang, D. Shen, and K. Wu, " Gap Waveguide PMC Packaging for a SIW-GCPW-Based Filter," IEEE Microwave and wireless components letters, vol. 26, no. 3, pp. 159-161, March 2016.

[32] Y. Miura, J. Hirokawa, M. Ando, Y. Shibuya, and G. Yoshida, "Doublelayer full-corporate-feed hollow-waveguide slot array antenna in the 60 GHz-band," IEEE Trans. Antennas Propag., vol. 59, no. 8, pp. 28442851, Aug. 2011.

[33] J. Wu, Y. J. Cheng, and Y. Fan, "60-GHz substrate integrated waveguide fed cavity-backed aperture-coupled microstrip patch antenna array," IEEE Trans. Antennas Propag., vol. 63, no. 3,pp. 1075-1085, March 2015.

[34] J. F. Xu, Z. N. Chen, X. M. Qing, and W. Hong, "Bandwidth enhancement for a $60 \mathrm{GHz}$ substrate integrated waveguide fed cavity array antenna on LTCC," IEEE Trans. Antennas Progag., vol. 59, no. 3, pp. 826-832, Mar.2011.

[35] J. Wu, Y. J. Cheng, and Y. Fan, "A wideband high gain high efficiency hybrid integrated plate array antenna for V-band inter satellite links," IEEE Trans. Antennas Propag., vol. 63, no. 4,pp. 1225-1233, April 2015.

[36] W. Liu, Z. N. Chen, and X. Qing, "60-GHz thin broadband high-gain LTCC metamaterial-mushroom antenna array," IEEE Trans. Antennas Propag., vol. 62, no. 9, pp. 4592-4601, Sep. 2014.

[37] A.U. Zaman, and P.-S. Kildal, "Gap Waveguides", Chapter in Z. N. Chen, D. Liu, H. Nakano, X. Qing, T. Zwick, Handbook of Antenna Technologies, pp. 3273-3347, Springer, 2016.

[38] A. Farahbakhsh, D. Zarifi, A. U. Zaman, P.-S. Kildal, "Corporate distribution networks for slot array antenna based on groove gap waveguide technology," $10^{\text {th }}$ European Conference on Antennas and Propagation (EuCAP), pp. 1-3, 2016. 